\title{
Determination of Antibacterial Ofloxacin in Human Serum Samples by a Resonance Light Scattering Technique with Alizarin Violet 3B
}

\author{
Zhanguang Chen, ${ }^{* \dagger}$ Yurui Peng,* Junhui Chen,** Taiyu Zhang, ${ }^{*}$ and Guoliang LIU* \\ *Department of Chemistry, Shantou University, Shantou 515063, China \\ **Medical College of Shantou University, Shantou 515031, China
}

\begin{abstract}
A method for the determination of ofloxacin (OFL) has been developed, based on the enhancement of resonance light scattering (RLS) of OFL in the presence of alizarin violet 3B (AV3B). Under the experimental conditions, the RLS intensity of AV3B was greatly enhanced by adding OFL. At pH 5.09, the enhancement of the RLS intensity at $439.5 \mathrm{~nm}$ was proportional to the concentration of OFL in the range $0.10-2.50 \mu \mathrm{g} / \mathrm{ml}$. The detection limit $(3 \sigma)$ was $0.013 \mu \mathrm{g} / \mathrm{ml}$. At $\mathrm{pH}$ 6.90, the enhancement of the RLS intensity at $405.0 \mathrm{~nm}$ was proportional to the concentration of OFL in the range $0.05-3.00 \mu \mathrm{g} / \mathrm{ml}$. The detection limit $(3 \sigma)$ was $0.021 \mu \mathrm{g} / \mathrm{ml}$. The proposed method with high sensitivity, selectivity and reproducibility was satisfactorily applied to the determination of OFL in human serum.
\end{abstract}

(Received July 14, 2008; Accepted September 1, 2008; Published July 10, 2009)

\section{Introduction}

Ofloxacin (OFL), 9-fluoro-2,3-dihydro-3-methyl-10-(4-methyl1-pierazinyl)-7-oxo-7H-pyrido[1,2,3-de]-1,4-benzoxazine-6carboxylic acid, Fig. 1, is one of the third-generation members of synthetic fluoroquinolone derivatives with antibacterial activity. This synthetic antibiotic is widely used in the treatment of urinary and respiratory tract infections and other infections, which are caught by Gram-positive and Gram-negative bacteria. ${ }^{1}$ The bactericidal activity of OFL results from inhibiting enzyme DNA gyrase required for bacterial DNA replication. ${ }^{2}$ Because the OFL main escretion pathway is urinary, only trace amounts are found in plasma. $^{3}$ Therefore, great attention was paid to study the possibility of exposure to low levels of this medicine.

Studies on determination of fluoroquinolones have attracted considerable interest in recent years. OFL is a synthetic fluoroquinolone, and the current analytical methods devoted to determination OFL were capillary electrophoresis, ${ }^{4}$ flow-injection spectrophotometry, ${ }^{5}$ flow-injection chemiluminescence, ${ }^{6,7}$ fluorescence spectrometry, ${ }^{8}$ thin layer chromatography, ${ }^{9}$ high-performance liquid chromatography (HPLC) ${ }^{10}$ and HPLC-fluorometry. ${ }^{11}$ However, these methods were limited in either complicated operation or sophisticated instrumentation or poor selectivity or poor limit of detection. Therefore, the development of a reliable, rapid and accurate method for the determination of OFL is of great importance.

Resonance light scattering (RLS) is a scattering-absorptionrescattering process that occurres when the wavelength of the incident beam exists in or close to the absorption band of the aggregation of particles. ${ }^{12,13}$ Based on this theory, Pasternack et al. first established a new technique (RLS) to study the

† To whom correspondence should be addressed.

E-mail:kqlu@stu.edu.cn aggregations of porphyrins by using a common fluorescence spectrometry. ${ }^{14-16}$ Huang et al. successfully applied this technique to the determination of nucleic acids at the nanogram level, and its detection limits were much lower than that of the fluorescence quenching method. ${ }^{17,18}$ From then on, this simple and sensitive method has been greatly used for analytical purposes. ${ }^{19,20}$ The RLS technique applied to the determination of nuclei acids, ${ }^{21-24}$ proteins, ${ }^{25-29}$ amino acid, ${ }^{30}$ metal ions ${ }^{31}$ and medicine ${ }^{32}$ has already been reported. This method has proved to be promising based on the enhanced RLS intensity of the assay system. The RLS technique is becoming a novel analytical method characterized with high sensitivity, rapidity and simplicity.

In this paper, the RLS spectra of alizarin violet 3B (AV3B) in the presence and absence of OFL are discussed. A reaction between AV3B and OFL occurred, and produced fine particles. The interaction between OFL and AV3B was also studied based on the absorption spectra, scanning electron micrograph and other analytical methods. The RLS signal was derived from fine particles of the formed complex,,$^{13,14}$ and the intensity was enhanced by increasing the OFL in the system. The enhancement of the RLS intensity was proportional to the OFL concentration. Based on the linear relationship, a simple and sensitive new assay was proposed for the routine determination of OFL in<smiles>CC1COc2c(N3CCN(C)CC3)c(F)cc3c(=O)c(C(=O)O)cn1c23</smiles>

Fig. 1 The structure of OFL. 

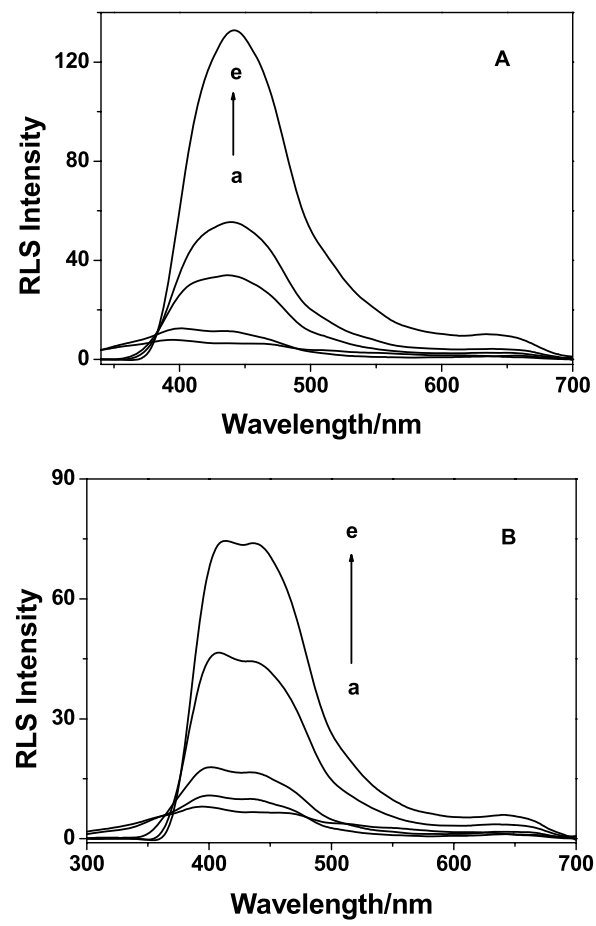

Fig. 2 RLS spectra of the OFL-AV3B system. (A) AV3B, $5.0 \times$ $10^{-5} \mathrm{M}$; OFL $(\mu \mathrm{g} / \mathrm{ml}$ ), (a) 1.0 (without AV3B), (b) 0, (c) 0.5, (d) 1.0, (e) $2.5 ; \mathrm{pH} 5.09$. (B) AV3B, $5.0 \times 10^{-5} \mathrm{M}$; OFL $(\mu \mathrm{g} / \mathrm{ml})$, (a) 1.0 (without AV3B), (b) 0, (c) 0.1, (d) 1.0, (e) 2.0; pH 6.90.

human serum samples. At pH values of 5.09 and 6.90 for Britton-Robinson (BR) buffer solutions, the RLS intensity of the AV3B system with OFL was rather stronger than that of a blank solution without OFL, and the enhanced RLS intensity was linear over a certain range of the OFL concentration. This assay was validated for the determination of OFL in human serum, and the results were obtained satisfactorily.

\section{Experimental}

\section{Apparatus}

All of the resonance light-scattering spectra were determined on an LS-55 spectrofluorometer (Perkin-Elmer, USA) with a 1 $\times 1 \mathrm{~cm}$ quartz cell. An Agilent 8453 ultraviolet spectrophotometer (Perkin-Elmer) was used to determine the absorption spectra of the different systems. The $\mathrm{pH}$ values of the solutions were recorded on a PHS-3C acidity meter (Leici, Shanghai). Scanning electron microscopy (SEM) images were obtained by Hitachi600 scanning electron microscopy (Tokyo, Japan).

\section{Materials}

All chemicals used were of analytical reagent grade, unless stated otherwise, and doubly distilled water was used throughout. OFL was purchased from Sigma and ofloxacin injection, $10 \mathrm{ml}$ : $0.2 \mathrm{~g}$ (Furen Medicine Group Co., Ltd.) was provided by Medical College of Shantou University. A stock solution of OFL was prepared by dissolving commercially purchased OFL, and the working solution was $10 \mu \mathrm{g} / \mathrm{ml}$ by diluting the OFL stock solution. They were all stored at approximately $4{ }^{\circ} \mathrm{C}$ in a refrigerator.

Alizarin violet 3B (AV3B) was obtained from Shanghai Kayon Biological Technology Co., Ltd. Its stock solution was
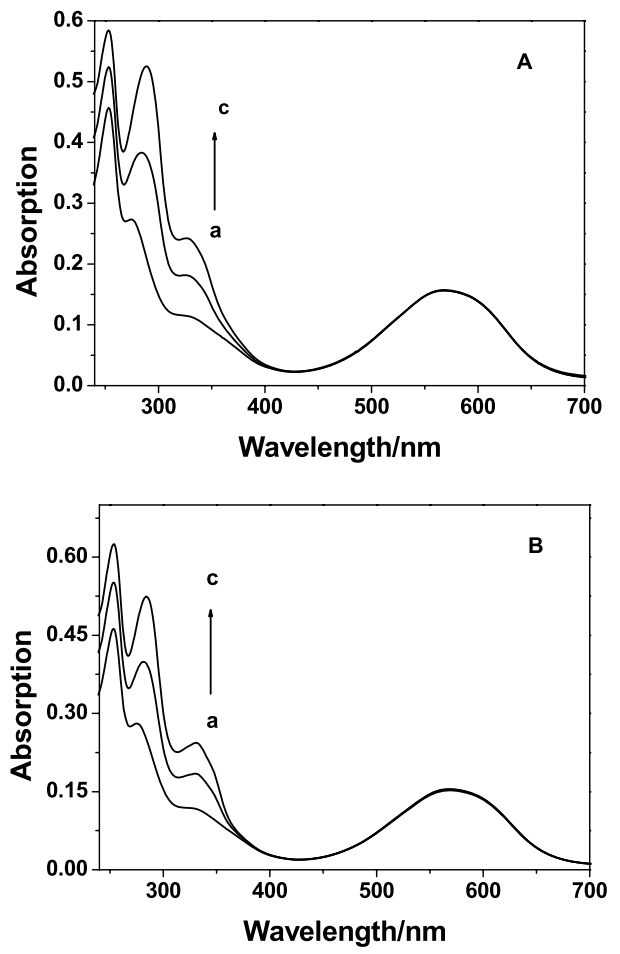

Fig. 3 Absorption spectra of AV3B in the presence of OFL. In the direction of the arrow, the absorption spectra were recorded for $0,0.1$, $0.5 \mu \mathrm{g} / \mathrm{ml}$ of OFL. AV3B, $5.0 \times 10^{-5} \mathrm{M}$; pH 5.09 (A) and $\mathrm{pH} 6.90$ (B), respectively (versus water).

prepared by dissolving the purchased produce in water, and the concentration of the working solutions was $5 \times 10^{-4} \mathrm{M}$.

The acidity of the solutions was controlled by BR buffer. The BR buffer solution was made up of $0.04 \mathrm{M}$ phosphoric acid, $0.04 \mathrm{M}$ acetic acid, $0.04 \mathrm{M}$ boric acid, and $0.2 \mathrm{M}$ sodium hydroxide. A $0.5 \mathrm{M} \mathrm{NaCl}$ solution was used to adjust the ionic strength of the assay solutions.

\section{General procedures}

Into a $10-\mathrm{ml}$ calibrated tube with a plug was added $1.0 \mathrm{ml}$ of a BR buffer solution, $1.0 \mathrm{ml}$ of AV3B and appropriate amounts of OFL or samples and stirred after each solution added. Then, the mixture was diluted to the mark by doubly distilled water and mixed thoroughly for determinations.

All RLS spectra were obtained by scanning simultaneously the excitation and emission monochromators $(\Delta \lambda=0.00 \mathrm{~nm})$ from 250.0 to $700.0 \mathrm{~nm}$ with excitation and emission slit widths of $5.0 \mathrm{~nm}$. The RLS intensity was determined at the maximum wavelength. The enhanced RLS intensity of the system by adding OFL is presented as $\Delta I_{\mathrm{RLS}}=I_{\mathrm{RLS}}-I_{\mathrm{RLS}}{ }^{0}$, where $\Delta I_{\mathrm{RLS}}$ is the enhancement of RLS intensity; $I_{\mathrm{RLS}}$ and $I_{\mathrm{RLS}}{ }^{0}$ are the RLS intensity of the system with and without OFL, respectively.

\section{Results and Discussion}

\section{Spectral characteristics}

Figure 2 displays the RLS spectra of the OFL-AV3B system at $\mathrm{pH} 5.09$ (A) and 6.90 (B), respectively. It can be seen that both the RLS intensity of AV3B and OFL are rather weak. However, the RLS intensity of AV3B can be greatly enhanced by adding OFL, and increases with an OFL concentration 


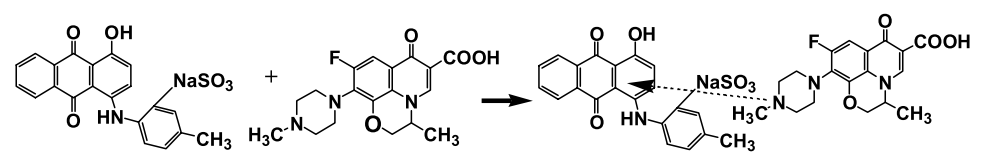

Scheme 1 The procedure of reaction between OFL and AV3B.

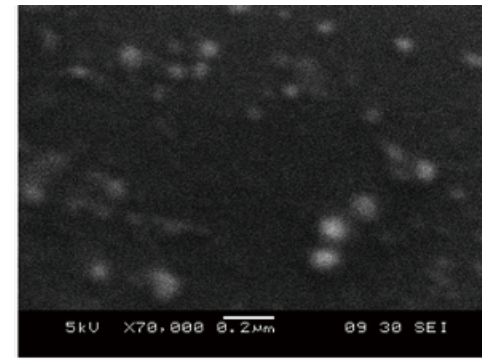

A

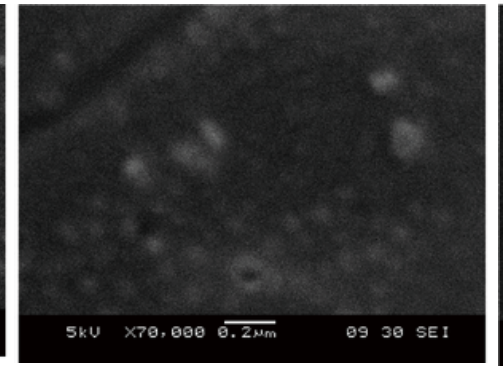

B

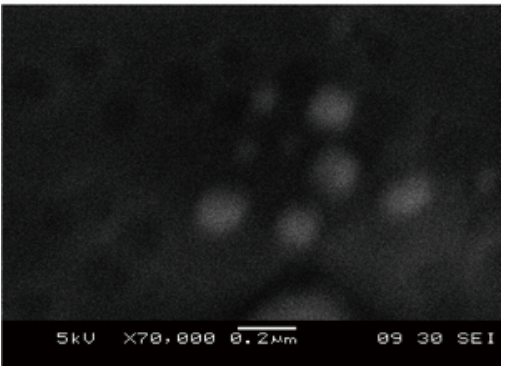

C

Fig. 4 Scanning electron micrograph of AV3B particles in the absence of OFL (A) and in the presence of OFL at pH 5.09 (B) and $\mathrm{pH} 6.90(\mathrm{C})$, respectively. Conditions: AV3B, $5.0 \times 10^{-5} \mathrm{M}$; OFL, $1.0 \mu \mathrm{g} / \mathrm{ml}$.

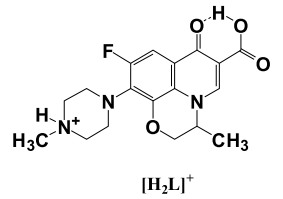

$\left[\mathbf{H}_{2} \mathbf{L}\right]^{+}$

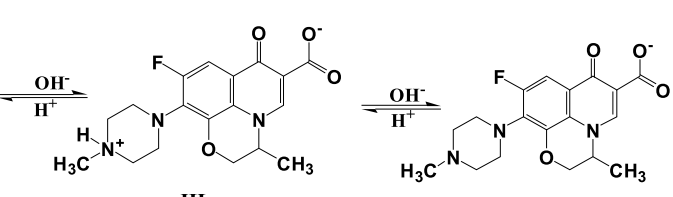

HL
$[\mathbf{L}]^{-}$

Scheme 2 The proton equilibrium procedure of OFL in aqueous solution with different $\mathrm{pH}$ values. increase. At $\mathrm{pH}$ values of 5.09 and 6.90, AV3B has a rather weak RLS peak near to 405.0 and $439.5 \mathrm{~nm}$, respectively.

Under the condition of $\mathrm{pH} 5.09$, the peak at $405.0 \mathrm{~nm}$ gradually disappeared, and the peak at $439.5 \mathrm{~nm}$ greatly increased with the addition of OFL. Under the condition $\mathrm{pH} 6.90$, with the addition of OFL, the RLS peak at $405.0 \mathrm{~nm}$ was more significant and more linear than that at $439.5 \mathrm{~nm}$. This indicated that reactions occurred between $\mathrm{OFL}$ and $\mathrm{AV} 3 \mathrm{~B}$ and formed the OFL-AV3B complex. The characteristics of the RLS spectra in Fig. 2 have not been reported before, so the reaction mechanism of between AV3B and OFL needed further study. In the present work the reaction of these two substances was studied at $\mathrm{pH}$ 5.09 and 6.90, respectively. The maximum RLS peak at $439.5 \mathrm{~nm}$ was selected for the analytical wavelength at $\mathrm{pH} 5.09$, and the maximum RLS peak at $405.0 \mathrm{~nm}$ was selected for the analytical wavelength at $\mathrm{pH} 6.90$.

The absorption spectra of the OFL-AV3B system were determined at $\mathrm{pH} 5.09$ (A) and 6.90 (B), and the results are displayed in Fig. 3. It can be found that the absorption intensity of AV3B increased with OFL addition with 3 distinct peaks located at 254, 276 and $569 \mathrm{~nm}$. A blue shift at $254 \mathrm{~nm}$ and a red shift at $276 \mathrm{~nm}$ appeared with increasing OFL. The intensity of the peaks both at 254 and $276 \mathrm{~nm}$ increased with increasing OFL. However, there was no influence on the peak at $569 \mathrm{~nm}$ due to the concentration of OFL. This phenomenon indicated that an interaction between AV3B and OFL occurred, and a novel complex was produced. The reaction mechanism can possibly depict as in Scheme 1. OFL possesses two relevant ionizable functional groups: a basic piperazinyl group and a carboxylic acid group. As an electron-donating group, the OFL molecular with a piperazinyl group can coordinate with AV3B, which is a plane-donor. In addition, the hydrogen bond and electrostatic force can also enhance the strength of the combination to form aggregations. Based on the scattering electron micrograph technique, the particles of $\mathrm{AV} 3 \mathrm{~B}$ and the complexes of the OFL-AV3B system were studied; the results are shown in Fig. 4. It can be seen that the particles in photo A uniformly distributed in the solution. However, in photos B and $\mathrm{C}$, larger particles obviously appeared. This indicated that the particles produced by the AV3B and OFL mixture are larger than that of $\mathrm{AV} 3 \mathrm{~B}$, and reactions between two materials occurred. According to the literatures, ${ }^{14}$ the RLS intensity of this system was remarkably enhanced mainly due to fine particles produced. A strong RLS signal was produced by the OFL-AV3B fine particles with large enough dimensions, which was proved by experiments discussed above.

\section{Effect of the $\mathrm{pH}$ and buffers}

As shown in Scheme 2, the acidity of the solution can change the molecule structure of OFL. Therefore, it can change the RLS spectra characteristics of the assay system. The effect of the solution acidity on the RLS intensity of the system is shown in Fig. 5. It can be seen that when the $\mathrm{pH}$ value was higher than 5.85 , the RLS spectra characteristics of the system changed. Therefore, when the $\mathrm{pH}$ value was lower than 5.85, the RLS intensity was determined at $439.5 \mathrm{~nm}$. When the $\mathrm{pH}$ value was higher than 5.85, the RLS intensity of the system was determined at $405 \mathrm{~nm}$. As it depicted in Fig. 5, the RLS intensity of AV3B 


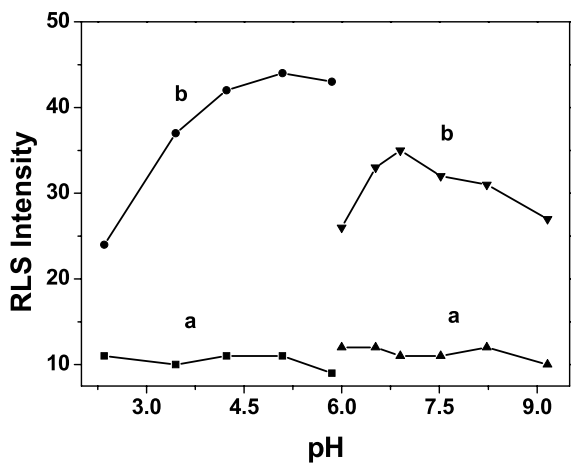

Fig. 5 Effect of the pH on the RLS intensity of the OFL-AV3B system. Conditions: AV3B, $5.0 \times 10^{-5} \mathrm{M}$; OFL, $1.0 \mu \mathrm{g} / \mathrm{ml}$. (a) $I_{\mathrm{RLS}}{ }^{0}$, (b) $\Delta I_{\text {RLS. }}$.

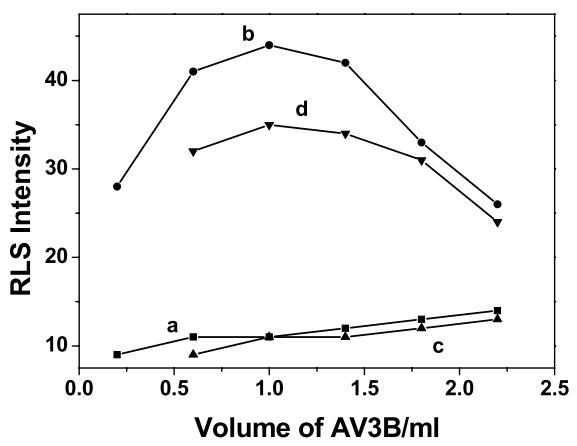

Fig. 6 Effect of the AV3B concentration on the RLS intensity of the OFL-AV3B system. Conditions: AV3B, $5.0 \times 10^{-5} \mathrm{M}$; OFL, $1.0 \mu \mathrm{g} / \mathrm{ml}$. (a) $I_{\mathrm{RLS}}{ }^{0}$, (b) $\Delta I_{\mathrm{RLS}}, \mathrm{pH} 5.09$, (c) $I_{\mathrm{RLS}}{ }^{0}$, (d) $\Delta I_{\mathrm{RLS}}, \mathrm{pH} 6.90$.

slightly changed with an acidity change. However, the RLS intensity of AV3B in the presence of OFL considerably changed with an acidity change. This phenomenon resulted from changing of the OFL molecule structure in the variational acidity solutions. The enhancement of the RLS intensity at $439.5 \mathrm{~nm}$ increased with increasing $\mathrm{pH}$ in a low $\mathrm{pH}$ level range, and reached its maximum in the $\mathrm{pH}$ range $4.23-5.85$. With the $\mathrm{pH}$ value further increasing, the enhancement of the RLS intensity at $405.5 \mathrm{~nm}$ increased, and reached maximum value in the $\mathrm{pH}$ range $6.50-8.23$. Henceforth, the enhancement of the RLS intensity decreased with increasing $\mathrm{pH}$. Therefore, the optimum $\mathrm{pH}$ was selected, respectively, at 5.09 and 6.90 for further study. Under the optimum condition, the influence of different buffers, such as the Britton-Robinson buffer, hexamethylene tetraminehydrogen chloride, and potassium biphthalate-hydrogen chloride were studied concerning the RLS signal of the determination systems. The results showed that the BR buffer was more beneficial to an enhancement of the RLS intensity. The BR buffer was employed for further study, and the optimum volume of the buffer was $1.0 \mathrm{ml}$.

\section{Effect of $A V 3 B$ concentration}

The effect on the RLS intensity of different AV3B concentrations was studied, and the results are shown in Fig. 6. It can be seen that the RLS intensity gradually increased when the AV3B concentration increased. At pH 5.09, the maximum and stable RLS signal was obtained with the AV3B volume in the range of $0.6-1.4 \mathrm{ml}$. At $\mathrm{pH} 6.90$, the maximum and stable RLS peak was obtained with the AV3B volume in the range of
Table 1 Effect of the potential foreign substances ${ }^{\mathrm{a}}$

\begin{tabular}{|c|c|c|c|}
\hline No. & Foreign substance & Concentration $/ \mu \mathrm{g} \mathrm{ml}^{-1}$ & Change in $\Delta I_{\mathrm{RLS}}, \%$ \\
\hline 1 & 1-Tyrosine & 20.0 & 1.9 \\
\hline 2 & 1-Glutamine & 20.0 & 1.4 \\
\hline 3 & 1-Aspartate & 20.0 & -0.8 \\
\hline 4 & 1-Proline & 20.0 & -2.6 \\
\hline 5 & 1-Cysteine & 20.0 & 1.4 \\
\hline 6 & 1-Leucine & 20.0 & -4.1 \\
\hline 7 & 1-Lysine & 20.0 & -1.3 \\
\hline 8 & 1-Histidine & 20.0 & -1.5 \\
\hline 9 & 1-Phenylalanine & 20.0 & -0.7 \\
\hline 10 & ctDNA & 30.0 & 2.2 \\
\hline 11 & yRNA & 30.0 & 1.0 \\
\hline 12 & Protein, $\mathrm{BSA}^{\mathrm{b}}$ & 30.0 & -2.4 \\
\hline 13 & Protein, $\mathrm{HSA}^{\mathrm{c}}$ & 30.0 & -3.1 \\
\hline 14 & $\mathrm{Fe}^{3+}, \mathrm{Cl}^{-}$ & 20.0 & 2.5 \\
\hline 15 & $\mathrm{~K}^{+}, \mathrm{Cl}^{-}$ & 20.0 & -1.8 \\
\hline 16 & $\mathrm{Sn}^{2+}, \mathrm{Cl}^{-}$ & 20.0 & 2.2 \\
\hline 17 & $\mathrm{Ag}^{+}, \mathrm{NO}_{3}^{-}$ & 20.0 & 2.4 \\
\hline 18 & $\mathrm{~Pb}^{2+}, \mathrm{NO}_{3}^{-}$ & 20.0 & -2.1 \\
\hline 19 & $\mathrm{Zn}^{2+}, \mathrm{Cl}^{-}$ & 20.0 & 2.7 \\
\hline 20 & $\mathrm{Ba}^{2+}, \mathrm{Cl}^{-}$ & 20.0 & -3.2 \\
\hline 21 & $\mathrm{Na}^{+}, \mathrm{Cl}^{-}$ & 20.0 & -1.6 \\
\hline 22 & $\mathrm{Mg}^{2+}, \mathrm{Cl}^{-}$ & 20.0 & 1.9 \\
\hline 23 & $\mathrm{Ca}^{2+}, \mathrm{Cl}^{-}$ & 20.0 & 3.3 \\
\hline 24 & $\mathrm{Mn}^{2+}, \mathrm{SO}_{4}^{2-}$ & 30.0 & -1.7 \\
\hline 25 & $\mathrm{Al}^{3+}, \mathrm{SO}_{4}^{2-}$ & 30.0 & 2.9 \\
\hline 26 & $\mathrm{~Pb}^{2+}, \mathrm{NO}_{3}^{-}$ & 30.0 & -1.1 \\
\hline 27 & $\mathrm{Cu}^{2+}, \mathrm{NO}_{3}^{-}$ & 30.0 & -1.6 \\
\hline 28 & Urea & 60.0 & 2.2 \\
\hline 29 & Glucose & 50.0 & -2.5 \\
\hline 30 & Sucrose & 50.0 & -1.3 \\
\hline 31 & Lactose & 50.0 & -2.6 \\
\hline 32 & $\mathrm{CTMAB}^{\mathrm{d}}$ & 30.0 & -2.2 \\
\hline
\end{tabular}

a. Conditions: OFL, $1.0 \mu \mathrm{g} / \mathrm{ml}$; AV3B, $5.0 \times 10^{-5} \mathrm{M}$.

b. Bovine serum albumin.

c. Human serum album.

d. Cetyltrimethylammonium bromide.

$0.6-1.8 \mathrm{ml}$. In a further study, a 1.0-ml AV3B volume was employed both at pH 5.09 and 6.90 .

\section{Incubation time and stability}

The stability of the reaction system was also studied by detecting the RLS intensity one time every $2 \mathrm{~min}$ at room temperature. The RLS intensity of OFL-AV3B reached a maximum for about $6 \mathrm{~min}$, and remained stable for about 110 min. The result showed that AV3B reacted with OFL rapidly, and that this system has good stability at room temperature.

\section{Interference of foreign substances on the RLS intensity}

Under the optimum conditions of the general procedure, the OFL-AV3B system with the potential foreign substances was tested; the results are given in Table 1. Most amino acids, proteins, sugars and metal ions can be tolerated at high concentrations. Thus, this method has high selectivity and practicability for quantitative analysis in human serum samples.

\section{Linear ranges and detection limits}

According to the above standard procedure, calibration curves were constructed; the results were summarized in Table 2 . The limits of detection were given by the equation $3 S_{0} / K$, where 3 is the factor at the $99 \%$ confidence level, $S_{0}$ is the standard 
Table 2 Analytical parameters of the assay ${ }^{a}$

\begin{tabular}{cccccc}
\hline $\mathrm{pH}$ & $\begin{array}{c}\lambda_{\max } / \\
\mathrm{nm}\end{array}$ & $\begin{array}{c}\text { Liniear } \\
\text { range/ } \\
\mu \mathrm{g} \mathrm{ml}^{-1}\end{array}$ & $\begin{array}{c}\text { Liniear regression } \\
\text { equation, } c / \\
\mu \mathrm{g} \mathrm{ml}^{-1}\end{array}$ & $\begin{array}{c}\text { Detection } \\
\text { limit, } 3 \sigma / \\
\mu \mathrm{g} \mathrm{ml}^{-1}\end{array}$ & $\begin{array}{c}\text { Correlation } \\
\text { coefficient, } r\end{array}$ \\
\hline 5.09 & 439.5 & $0.10-2.50$ & $Y=-3.68+49.72 c$ & 0.013 & $0.9997(n=9)$ \\
6.90 & 405.0 & $0.05-3.00$ & $Y=4.93+29.97 c$ & 0.021 & $0.9994(n=10)$ \\
\hline
\end{tabular}

a. Condition: AV3B, $5.0 \times 10^{-5} \mathrm{M}$.

Table 3 Comparison of various methods for the determination of OFL

\begin{tabular}{lcc}
\hline \multicolumn{1}{c}{ Method } & $\begin{array}{c}\text { Detection limit, } \\
3 \sigma / \mu \mathrm{g} \mathrm{ml}^{-1}\end{array}$ & Ref. \\
\hline RLS & $0.013^{\mathrm{a} / 0.021^{\mathrm{b}}}$ & This work \\
CE $^{\mathrm{c}}$ & 8.5 & 4 \\
Flow-injection spectrophotometry & $0.72\left(2.0 \times 10^{-6} \mathrm{M}\right)$ & 5 \\
Flow-injection chemiluminescence & $0.0398\left(1.1 \times 10^{-7} \mathrm{M}\right)$ & 7 \\
Spectrofluorometry & 0.14 & 8 \\
HPLC & 0.0625 & 10 \\
Bioassay & 0.125 & 10 \\
HPLC-fluorometry & 0.0252 & 11 \\
\hline
\end{tabular}

a. b. Detection limit at pH 5.09 and 6.90, respectively.

c. Capillary electrophoresis.

deviation of the blank measurements $(n=16)$, and $K$ is the slope of the calibration curve.

This method was compared with other reported methods applied to the determination of OFL in real samples; the results of the sensitivity are given in Table 3 . The sensitivity of this method is much higher than that of spectrofluorometry. Also the detection limit by this method is nearly 5-times lower than that by HPLC, which has a very low detection limit. It indicated that the proposed method provided a sufficient sensitivity for the quantification of trace OFL in human serum. Therefore, this investigation will be valuable for studying OFL and conducting practical tests.

\section{Analytical applications}

Rate of recovery and precision. Under the optimal experimental conditions, the validity of the method was confirmed by applying the standard addition method technique to determination the recovery and precision of OFL in human serum. A volunteer was a healthy student from Shantou University; his heart, liver and kidney were examined and shown to be well before testing. And the volunteer can not take any medicines for 14 days before the testing day; $5 \mathrm{ml}$ of blood was taken from the object and anticoagulated with heparin. The mixture was then centrifugated (20 min at $4000 \mathrm{rpm}$ ) to obtain serum, which was transferred into a 100-ml flask, and diluted to the mark with water and stored at $4^{\circ} \mathrm{C}$. A suitable volume of the solution appropriately spiked with the standard OFL solution was taken, and three different samples with different OFL concentrations were obtained for analysis. The relative standard deviation (RSD) was calculated and is given in Table 4 . The recovery levels of the method were close to $100 \%$ in all cases and the RSD was just between 1.0 and $4.2 \%$.

Analytically, the proposed method with high accuracy and good precision are suitable for a trace determination of OFL in human serum.

Measurement of real samples. Under the optimal experimental
Table 4 Day-to-day and within-day precision and accuracy study for determination of OFL

\begin{tabular}{|c|c|c|c|c|c|c|}
\hline \multirow[b]{2}{*}{$\begin{array}{l}\text { Added/ } \\
\mu \mathrm{g} \mathrm{ml}^{-1}\end{array}$} & \multicolumn{3}{|c|}{ Day-to-day $(n=5)$} & \multicolumn{3}{|c|}{ Within-day $(n=5)$} \\
\hline & $\begin{array}{c}\text { Found } \pm \\
\mathrm{SD} / \\
\mu \mathrm{g} \mathrm{ml}^{-1}\end{array}$ & RSD & $\begin{array}{c}\text { Rec., } \\
\%\end{array}$ & $\begin{array}{c}\text { Found } \pm \\
\mathrm{SD} / \\
\mu \mathrm{g} \mathrm{ml}^{-1}\end{array}$ & RSD & $\begin{array}{c}\text { Rec., } \\
\%\end{array}$ \\
\hline \multicolumn{7}{|l|}{ pH 5.09} \\
\hline 0.50 & $0.50 \pm 0.01$ & 2.0 & 100.0 & $0.48 \pm 0.02$ & 4.1 & 96.0 \\
\hline 1.50 & $1.47 \pm 0.05$ & 3.4 & 98.0 & $1.47 \pm 0.03$ & 2.0 & 98.0 \\
\hline 2.00 & $1.93 \pm 0.04$ & 2.1 & 96.5 & $1.94 \pm 0.05$ & 2.6 & 97.0 \\
\hline \multicolumn{7}{|l|}{ pH 6.90} \\
\hline 0.50 & $0.48 \pm 0.02$ & 4.2 & 96.0 & $0.48 \pm 0.01$ & 2.1 & 96.0 \\
\hline 1.50 & $1.51 \pm 0.04$ & 2.6 & 100.7 & $1.47 \pm 0.05$ & 3.4 & 98.0 \\
\hline 2.00 & $1.98 \pm 0.03$ & 1.5 & 99.0 & $1.97 \pm 0.04$ & 1.0 & 98.5 \\
\hline
\end{tabular}

Table 5 Results for the determination of OFL in human serum

\begin{tabular}{cccc}
\hline Added $/ \mu \mathrm{g} \mathrm{ml}^{-1}$ & Found $\pm \mathrm{SD} / \mu \mathrm{g} \mathrm{ml}^{-1}$ & RSD & Recovery, \% $(n=5)$ \\
\hline 0 & $0.98 \pm 0.04$ & 4.1 & - \\
1.50 & $2.41 \pm 0.07$ & 2.9 & 97.2 \\
0.50 & $1.46 \pm 0.03$ & 2.1 & 98.6 \\
\hline
\end{tabular}

conditions, the proposed method was carried out for the determination of the OFL in serum samples. The unit dose drug was injected into a vein of a volunteer at a constant velocity for about half an hour. Four hours after using medicine, $5 \mathrm{ml}$ blood was taken from the object and analyzed following the procedure described in section Rate of recovery and precision. The obtained results are given in Table 5. This method was applied to analysis of OFL in the human serum with satisfactory results.

\section{Conclusion}

A novel, sensitive, simple, practical and selective method for the determination of trace amounts of OFL has been developed. It is based on a remarkable enhancement of the RLS intensity, which results from the reaction between OFL and AV3B, and large particles are produced. Under the optimum condition, the determinations of all systems, including the real samples, were investigated and satisfactory results were obtained. The simplicity of the procedure was just applied on a common spectrophotofluorometer. The reagent AV3B was very cheap. Compared to other methods, the sensitivity of the proposed method was much higher, and the detection limits reached to $0.013 \mu \mathrm{g} / \mathrm{ml}$ at pH 5.09 and $0.021 \mu \mathrm{g} / \mathrm{ml}$ at $\mathrm{pH} 6.90$, respectively. In addition, as for the tolerance of foreign substances, the proposed method supplied a high selectivity for the determinations of real samples. Therefore, the present study indicates that the RLS technique is a promising and practical tool for developing a quantitative method in biochemistry analytical and clinical fields.

\section{Acknowledgements}

All of the authors express their sincere thanks for support from the National High Technology Research and Development Program (863) Foundation of China (No. 2003AA2Z3162) and the Municipal Science Foundation of Shantou (No. S2002023). 


\section{References}

1. N. Ichihara, H. Tachizawa, M. Tsumura, T. Une, and K. Sato, Chemotherapy, 1984, 32, 118.

2. K. Sato, U. Matsuura, M. Inone, T. Ueno, Y. Osada, H. Ogawa, and M. Mitsuhashi, Antimicrob. Agents Chemother., 1982, 22, 548.

3. J. A. Murillo, A. Alañón Molina, A. Muñoz de la Peña, I. Durán Merás, and A. Jiménez Girón, J. Fluoresc., 2007, 17, 481.

4. S. S. Zhang, H. X. Liu, Y. J. Wu, and C. L. Yu, Analyst, 2001, 126, 441.

5. M. Soledad García, M. Isabel Albero, C. Sánchez-Pedreño, and M. S. Abuherba, Eur. J. Pharm. Biopharma., 2005, 61, 87.

6. H. W. Sun, L. Q. Li, and X. Y. Chen, Anal. Sci., 2006, 22, 1145.

7. Y. D. Liang, J. F. Song, and X. F. Yang, Anal. Chim. Acta, 2004, 510, 21.

8. O. Ballesteros, J. L. Vilchez, and A. Navalon, J. Pharm. Biomed. Anal., 2002, 30, 1103.

9. S. Thangadurai, S. K. Shukla, and Y. Anjaneyulu, Anal. Sci., 2002, 18, 97.

10. L. R. Zhang, N. N. Cheng, B. Y. Chen, and Y. M. Wang, Chin. J. New Drugs Clinic Remed., 2003, 22, 201.

11. A. Espinosa Mansilla, A. Muñoz de la Peña, D. González Gómez, and F. Salinas López, Talanta, 2006, 68, 1215.

12. C. Z. Huang and Y. F. Li, Anal. Chim. Acta, 2003, 500, 105.

13. Y. F. Li, C. Z. Huang, and X. L. Hu, Chin. J. Anal. Chem., 1998, 26, 1508.

14. R. F. Pasternack, C. Bustamante, P. J. Collings, A. Giannetto, and E. J. Gibbs, J. Am. Chem. Soc., 1993, 115, 5393.

15. R. F. Pasternack, K. F. Schaefer, and P. Hambright, Inorg. Chem., 1994, 33, 2062.
16. R. F. Pasternack and P. J. Collings, Science, 1995, 269 , 935.

17. C. Z. Huang, K. A. Li, and S. Y. Tong, Anal. Chem., 1996 $68,2259$.

18. C. Z. Huang, K. A. Li, and S. Y. Tong, Anal. Chem., 1997, 69,514

19. J. Ling, C. Z. Huang, Y. F. Li, Y. F. Long, and Q. G. Liao, Appl. Spectrosc. Rev., 2007, 42, 177.

20. W. Lu, B. S. Fernández Band, Y. Yu, Q. G. Li, J. C. Shang, C. Wang, Y. Fang, R. Tian, L. P. Zhou, L. L. Sun, Y. Tang, S. H. Jing, W. Huang, and J. P. Zhang, Microchim. Acta, 2007, 158, 29.

21. P. Bao, A. G. Frutos, C. Greef, J. Lahiri, U. Muller, T. C. Peterson, L. Warden, and X. Y. Xie, Anal. Chem., 2002, 74, 1792.

22. Z. G. Chen, W. F. Ding, F. L. Ren, J. B. Liu, and Y. Z. Liang, Anal. Chim. Acta, 2005, 550, 204.

23. Z. G. Chen, W. F. Ding, F. L. Ren, Y. L. Han, and J. B. Liu, Anal. Lett., 2005, 38, 2301.

24. Z. G. Chen, T. Y. Zhang, X. M. Chen, Y. L. Han, and L. Zhu, Microchim. Acta, 2007, 157, 107.

25. S. P. Liu, R. Yang, and Q. Liu, Anal. Sci., 2001, 17, 243.

26. Z. G. Chen, J. B. Liu, Y. Z. Liang, and F. L. Ren, J. Biomol. Screen., 2006, 11, 400.

27. Z. G. Chen, T. Y. Zhang, F. L. Ren, and W. F. Ding, Microchim. Acta, 2006, 153, 65.

28. Z. G. Chen, J. B. Liu, and Y. L. Han, Talanta, 2007, 71, 1246.

29. Z. G. Chen, J. B. Liu, T. Y. Zhang, and Y. L. Han, Anal. Sci., 2007, 23, 1305.

30. Z. G. Chen, J. B. Liu, Y. L. Han, and L. Zhu, Anal. Chim. Acta, 2006, 570, 109.

31. S. P. Liu, Z. F. Liu, and C. Z. Huang, Anal. Sci., 1998, 14, 799.

32. Z. G. Chen, Y. R. Peng, J. H. Chen, and L. Zhu, J. Pharm. Biomed. Anal., 2008, 48, 946. 